\title{
A PARTICIPAÇÃO E A GESTÃo DEMOCRÁTICA NO PROGRAMA NACIONAL DE FORTALECIMENTO DOS CONSELHOS ESCOLARES
}

\author{
MORAES, Aline C. A. ${ }^{1}$ \\ Universidade Estadual de Londrina \\ alinemoraes.edu@gmail.com \\ RUIZ, Maria José Ferreira. ${ }^{2}$ \\ Universidade Estadual de Londrina \\ fruiz@uel.br
}

Eixo Temático 01: Políticas Públicas e Gestão da Educação

\section{RESUMO}

Este artigo tem como objetivo analisar a concepção de participação e de gestão democrática disseminada por meio do Programa Nacional de Fortalecimento dos Conselhos Escolares (PNFCE) e discutir a relevância do fortalecimento do referido conselho. Na pesquisa utilizamos como recursos metodológicos a pesquisa documental nos cadernos instrucionais elaborados pelo MEC/SEB; a pesquisa bibliográfica e a análise em relatos de "experiências exitosas" de escolas que adotaram tal programa. Neste texto, a princípio apresentamos a concepção de conselhos escolares e discutimos sobre o processo político que possibilitou a inserção deste colegiado nas políticas educacionais, mais especificamente na LDBEN 9394/96. A seguir apresentamos uma análise a respeito da concepção de gestão democrática do Programa Nacional de Fortalecimento dos Conselhos Escolares, evidenciando que a mesma se constitui num processo que para ser efetivado solicita mudanças organizacionais e políticas na sociedade. Concluímos que a concepção de gestão democrática e de participação, difundida pelo PNFCE se pauta na lógica das políticas para a educação difundidas após a década de 1990, na qual a parceria entre escola e comunidade é vista como condição sem a qual não é possível alcançar a qualidade na escola. Contudo é necessário questionar sobre essa concepção redentora e também sobre as condições concretas e objetivas diante das quais a gestão democrática é efetivada

Palavras-chave: Conselho Escolar; Gestão Democrática; Participação.

\footnotetext{
Abstract: This article aims to analyze the concept of participation and democratic management disseminated through the National Program for the Strengthening of School Boards (PNFCE) and discuss the importance of strengthening the board. In the survey we used as methodological resources to documentary research in instructional booklets prepared by the MEC / SEB; bibliographical research and analysis in reports of

${ }^{1}$ Graduanda em Pedagogia - Departamento de Educação - Universidade Estadual de Londrina -UEL. 86055-680. Londrina-ParanáBrasil. Alinemoraes.edu @ gmail.com. Integrante Projeto de Iniciação Científica Gestão Democrática: a participação das organizações populares de bairros na gestão da escola pública de periferia urbana.

${ }^{2}$ Docente da Universidade Estadual de Londrina. Departamento de Educação - Universidade Estadual de Londrina -UEL. 86055680.Londrina-Paraná- Brasil. Fruiz@uel.br. Doutora em Educação pela UNESP-Marília. Coordenadora do Projeto de Pesquisa: Gestão Democrática: a participação das organizações populares de bairros na gestão da escola pública de periferia urbana
} 
"successful experiences" of schools that have adopted such a program. In this paper, at first we present the design of school boards and discuss the political process that led to the insertion of this collegiate educational policies, specifically in LDBEN 9394/96. Following is an analysis about the concept of democratic management of the National Program for the Strengthening of School Boards, showing that it constitutes a process that calls to be made effective organizational and political changes in society. We conclude that the concept of democratic management and participation, disseminated by PNFCE is guided in the logic of policies for widespread education after the 1990s, in which the partnership between school and community is seen as a condition without which it is not possible to achieve quality in school. But we must question about this redemptive design and also on the concrete and objective conditions before which the democratic management is effective

Keywords: School Board; Democratic management; Participation.

\section{Introdução}

Os anos de 1980, no Brasil, foram marcados por disputas políticas e econômicas, emergindo com elas uma caraterização social, na qual a sociedade volta a reivindicar o direito à participação social. É cenário no qual os movimentos populares, novamente, se multiplicam por todo país. Neste contexto de reinvindicações de direito à participação é que os conselhos, núcleos organizados como órgãos de representação da sociedade, voltam a ser evidenciados, como espaços de lutas políticas e de controle social, que fazem mediação entre Estado e sociedade, em prol do cuidado com a coisa pública. Estas reinvindicações sociais almejam ampliar a participação popular, restringida pelo Estado no período ditatorial, o que contribuiu para fomentar o levante das organizações populares, que reivindicam por melhores condições de trabalho, de vida e por uma educação de qualidade. Esse contexto propiciou conquistas que foram registradas na Constituição de 1988.

Benevides (1991) nos aponta que a Constituição Federal de 1988 prevê a participação direta ou indireta do cidadão, propondo assim os conselhos e outros órgãos colegiados, nos quais os cidadãos exerçam sua representatividade social e apresentem suas reivindicações, num modelo de democracia republicana/representativa.

Essa identidade de propósitos, no que toca a participação da sociedade civil, é evidentemente aparente. Mas essa aparência é sólida e cuidadosamente construída através da utilização e referências comuns que tornam seu deciframento uma tarefa difícil, especialmente para atores da sociedade civil envolvidos, cuja participação se apela tão veementemente e em termos familiares tão sedutores (DAGNINO, 2004, p. 97). 
Dessa forma, as concepções de participação social, de autonomia e outra mais, que compõem a concepção dos teóricos e dos trabalhadores da educação que têm uma concepção progressista de sociedade, almejando transformações sociais substantivas, são apropriados e recebem novos significados, ao gosto dos pressupostos neoliberais e conservadores. Essa constatação não inviabiliza, contudo, a prática dos conselhos que, mesmo de forma limitada, são órgãos coletivos que possibilitam a ação da sociedade, contribuindo e fiscalizando as políticas públicas, sejam elas voltadas para a educação, para a saúde ou para qualquer outro área social.

Segundo Cury (2000, p. 47) a palavra conselho "vem do latim conselium, que por sua vez provem do verbo consulo/consulere, significando tanto ouvir alguém quanto submeter algo a uma deliberação de alguém após algumas ponderações refletidas, prudentes e de bom senso". Estes instrumentos de democracia fazem parte da gestão democrática da educação. O princípio da gestão democrática do serviço público foi contemplado na CF de 1988 e reiterado na LDB 9394/96, em seu artigo 14. Este artigo institui a participação da comunidade escolar e local no conselho escolar, e a elaboração coletiva do projeto político-pedagógico da escola. O funcionamento efetivo dos conselhos escolares pode contribuir para a descentralização do poder de decisão, que deixaria de estar centrado na figura do diretor escolar, passando para as mãos do coletivo.

Contudo, a gestão democrática não é algo a ser imposto de cima para baixo, por força de um marco legal. Segundo Dourado (1998, p. 79): ” a gestão democrática é um processo de aprendizado e de luta que vislumbra nas especificidades da prática social e em sua relativa autonomia, a possibilidade de criação de meios de efetiva participação de toda a comunidade escolar na gestão da escola."

Ela se faz em um processo político, ativo, dinâmico e dialético, no qual pairam interesses contraditórios. Se por um lado ela é conquista dos trabalhadores da educação e possiblidade de alargamento da participação destes na escola, por outro ela também se apresenta como forma de atribuir à escola e seus atores, a responsabilidade da manutenção, inclusive financeira, desta instituição.

Nessa direção, há o incentivo por parte das políticas governamentais à participação passiva da sociedade na escola, de forma voluntária, conforme fomentado no modelo neoliberal de parceria público-privado. Esse movimento foi implementado no Brasil, em meado da década de 1990, com a elaboração do Plano Diretor da Reforma do Estado no Brasil, que defendeu a minimização do papel do Estado no desenvolvimento 
de suas ações, naquilo que diz respeito ao fomento das políticas públicas. Seguiu-se daí um processo crescente de descentralização de execução de tarefas organizacionais, mas um processo de centralização das tomadas de decisão e, também, um processo de avaliação em larga escala, ou seja, o Estado se retira aos poucos do seu papel de provedor de recursos para ser o fiscalizador de resultados.

Esse processo ocorre, concomitantemente, ao processo de reestruturação produtiva e de um novo modo de organização do mundo do trabalho, que ficou conhecido como acumulação flexível (HARVEY, 1992). Neste contexto, estimula-se um modelo de Estado que minimize suas intervenções no setor produtivo, incitando a demanda de crescimento do setor privado. Dentro desta lógica, é necessário também que o Estado diminua sua atuação nas áreas sociais e estabeleça parcerias com a sociedade a fim de minimizar o ônus com os serviços públicos, refutando o modelo de Estado de bem-estar social e estimulando a filantropia.

Contudo, mesmo com essa ambiguidade a respeito da gestão democrática defendemos que a participação política, em seu sentido pleno, se caracteriza pela força coletiva de uma atuação consciente dos sujeitos sociais, por meio da qual os membros de um grupo, reconhecem e assumem o poder de exercer influência nos assuntos da vida coletiva. Este poder resulta da vontade coletiva de compreender, decidir e agir sobre as questões que os afetam direta e/ou indiretamente e talvez não possa ser efetivado em sua plenitude na sociedade de classes.

É neste propósito que a participação popular na escola assume uma caracterização política e salutar e pode contribuir para melhorar a sua qualidade. Com isto a escola tornase um espaço de luta política que visa garantir a aproximação dos estudantes com o conhecimento científico elaborado pela sociedade. Dessa forma, não se trata de negar a importância da participação da comunidade nos colegiados escolares, como no caso do conselho escolar, mas sim de esclarecer que essa participação não pode ser ingênua e manipulada pelos interesses da classe hegemônica. Não é apenas a participação da comunidade na escola que vai melhorar a sua qualidade. Ela é importante, entretanto, a escola pública não pode prescindir dos recursos públicos para sua qualidade e manutenção, e ainda segundo Gohn (2004), existem algumas premissas que sustentam isso

Existem, também algumas premissas básicas relativas à participação da sociedade civil das quais se destaca a participação da sociedade civil na esfera pública- via conselhos e outras formas institucionalizadas - não é para substituir o Estado, mas para lutar 
para que este cumpra seu dever: propiciar educação, saúde e demais serviços sociais com qualidade, e para todos. Essa participação deve ser ativa e considerar a experiência de cada cidadão que nela se insere e não tratá-los como corpos amorfos a serem enquadrados em estruturas prévias, num modelo pragmatista.

A criação de conselhos não pode ser vista apenas como estratégia de desresponsabilizarão do governo, embora também o seja, mas sim precisa ser analisada no contexto "das políticas da democracia participativa e como estratégia de organização de um poder autônomo, estruturado a partir dos movimentos sociais da sociedade civil" (GOHN, 2001, p. 75).

De acordo com Paro (2002) a gestão democrática pede uma mudança no modo de entender o ato de administrar, principalmente, em uma sociedade que ainda carrega os resquícios do autoritarismo. Precisamos avançar na concepção do exercício do poder na escola pública, poder este que deve estar para servir a comunidade e não aos interesses da classe hegemônica. Para este autor, "é na prática escolar cotidiana que precisam ser enfrentados os determinantes mais imediatos do autoritarismo enquanto manifestações, num espaço restrito, dos determinantes estruturais mais amplos da sociedade" (PARO, 2002, p.19).

$\mathrm{Na}$ tentativa de fomentar a ação dos conselhos escolares nas escolas públicas o MEC institui em 2004 a Programa Nacional dos Conselhos Escolares, que foi sancionado pela Secretaria de Educação Básica, por meio da Coordenação-Geral de Articulação e Fortalecimento Institucional dos Sistemas de Ensino, mediante a Portaria Ministerial $\mathrm{n}^{\mathrm{o}}$ 2.896/2004. Este Programa faz compõe uma das ações do "Plano de Metas Compromisso Todos pela Educação", instituído pelo MEC na gestão Lula.

O PNFCE tem como principal objetivo fortalecer a prática de conselhos escolares, tendo como foco a formação continuada dos conselheiros escolares, assim como dos técnicos que atuam em secretarias de educação (municipais e estaduais). Essa formação pode ser presencial e/ou à distância. Desde sua implantação já foram elaborados doze cadernos com textos fundamentados em discussões teóricas acerca do tema gestão democrática e outras discussões a fim. Essa formação é organizada em sistema de parceria entre a coordenação do PNFCE, as secretarias de educação e algumas instituições de ensino superior (RUIZ, 2013).

O Programa Nacional de Fortalecimento dos Conselhos apresenta algumas normatizações que estabelecem as competências dos conselhos escolares, dentre estas: 
1. Função deliberativa é entendida quando a lei atribui ao conselho competências para decidir, em instância final, sobre determinadas questões.

2. Função consultiva tem caráter de assessoramento e é exercido por meio de pareceres, aprovado pelo colegiado.

3. Função fiscal que ocorre quando o conselho é revestido para fiscalizar o cumprimento de normas e a legalidade ou legitimidade de ações, aprová-las ou determinar providências para sua alteração.

4. Função mobilizadora situa o conselho numa ação efetiva de mediação entre o governo e a sociedade, promovendo os direitos educacionais da cidadania, ou seja: da qualidade da educação (BRASIL, 2004).

Segundo o PNFCE, os conselhos escolares, quando ativos, cumprem com a função de orientar a direção sobre assuntos relacionados ao processo de ensino e de aprendizagem e os demais assuntos pedagógicos e administrativos que compõem o cotidiano das escolas. As escolas que decidem pela implementação do Programa, podem incluir alterações que atendam às suas especificidades e as deliberações coletivas. Ainda na perspectiva deste Programa, os conselhos escolares são mecanismos favorecedores a uma gestão escolar democrática e têm por finalidade propor espaços de tomada de decisões conjuntas, haja vista a procura de meios para alcance dos objetivos escolares, em todos os seus aspectos, pela participação de modo ativo de pais, alunos, professores e funcionários. Este instrumento democrático não pode estar para autenticar a voz da direção, como ocorre em grande parte das vezes, mas sim para construir a voz da pluralidade e paridade dos sujeitos sociais, pertencentes às escolas. Os participantes do conselho representam a comunidade escolar e local, atuando em confluência com a administração escolar e definindo meios para a tomada das decisões administrativas, financeiras e político-pedagógicas que venham condizer com as necessidades e as potencialidades da escola.

A partir da sucinta apresentação que fizemos até aqui sobre o PNFCE, na sequência, apresentamos uma breve análise dos relatos de "experiências exitosas" registradas por escolas que se inscreveram para participar do PNFCE. Esses relatos ficaram disponíveis no site do MEC por um certo período, mas atualmente, não se encontram mais ali registradas, por motivos desconhecidos. Como era de interesse para nosso estudo, fizemos a compilação destes dados que servirão para captarmos qual a concepção de gestão democrática e participação que permeia as escolas, na implementação deste Programa. Contudo, uma análise mais aprofundada pediria uma 
pesquisa empírica e observação no campo (nestas escolas), para podermos observar melhor se tais experiências são de fato exitosas, uma vez que os dados relatados, muitas vezes, omitem a questão política. Porém, ressaltamos que nenhum tipo de participação em colegiados é neutro, mas sim carregado de lutas políticas e embates com o poder local. Tal como posto por Muller e Surel (2002, p.77)

A construção das políticas públicas não é um processo abstrato. Ela é ao contrário, indissociável da ação dos indivíduos ou dos grupos envolvidos, de sua capacidade de produzir discursos concorrentes, de seus modos de mobilização. Ela depende também, de estrutura mais ou menos flutuante de suas relações e das estratégias elaboradas nos contexto de ação definidos em especial pelas estruturas institucionais, no interior das quais tomam lugar as políticas públicas.

Portanto, reconhecemos que nossa análise é parcial, uma vez que se embasa em relatos que precisariam ser confirmados na prática social de cada escola, a fim de perceber o contexto dessas escolas, sua estrutura de poder, de participação e outros intervenientes que nos permitiriam compreender melhor esse fenômeno. É por reconhecer esse limite que optamos deixar o termo "experiências exitosas" entre aspas.

As “experiências exitosas", inseridas no banco de dados do programa, nos aponta a frágil concepção de participação difundida nos conselhos escolares das escolas pesquisadas, ora se apresenta como uma participação de caráter apenas consultivo (ouvir argumentos sobre determinados assuntos) e/ou informativo (colocar os sujeitos a par de algo que já havia sido decidido), ora como uma participação crítica e ativa de sujeitos sociais autônomos no encaminhamento de seus argumentos e contra-argumentos.

Porém acreditamos que participação ao nosso ver, é a que mais contribui para auxiliar na conquista de uma escola pública de qualidade, uma vez que une forças com a escola em prol de reivindicar o direito ao acesso e à permanência nessa instituição.

Só se pode aprender a democracia por meio do fazer e da vivência de processos e espaços participativos avaliados, constantemente, em sua qualidade democrática: a aprendizagem conceitual e teórica da democracia tem, na verdade, menor relevância nesse processo. A participação adulta pode ser prognosticada pela participação como estudante, daí a importância da escola dedicar tempo para fazer democracia e promover a participação. (WERLE, 2003, p. 24).

Na cidade de Araucária - PR, o relato analisado descreve que a formação no PNFCE fomentou a implantação da gestão democrática nas escolas municipais da região, fazendo com que estas percebesse a necessidade de iniciar a construção de um processo 
coletivo de participação nas tomadas de decisão em seu interior. Nesta escola, há relatos de que o desenvolvimento das ações propostas pelo PNFCE e repassadas aos gestores por intermédio da Secretaria Municipal de Educação possibilitou ao menos a tentativa de um exercício democrático e coletivo de efetivação do conselho escolar, antes não atuantes nas escolas municipais daquela região. $O$ diretor de uma das escolas municipais analisadas ressalta que "O mais importante é compreender que está construção não se efetiva por decreto, portaria ou resoluções, mas sim é resultante, sobretudo da concepção de gestão democrática difundido pelo PNFCE.” (DIRETOR, 1).

Neste relato podemos observar que, aparentemente, a formação obtida no referido Programa teve algum êxito e tem conseguido ampliar a concepção da gestão democrática e daquela comunidade escolar. No entanto, concordamos com Dourado quando afirma que a gestão democrática

[...] só se efetiva se a gestão dos processos for participativa, ou seja, se houver participação ativa de todos os atores e instituições intervenientes nos processos de gestão. É nesse espaço ambíguo que devemos pensar os limites $\mathrm{e}$ as possibilidades de democratização na escola, ou seja, é fundamental não perder de vista que a educação como prática social é parte constitutiva e constituinte das relações sociais mais amplas (DOURADO, 2007, p. 150).

Portanto, há que se considerar que essas relações sociais mais amplas, as quais o autor se refere, ocorrem no contexto da sociedade capitalista neoliberal, que tem uma perspectiva de gestão empresarial. Importa, portanto, a busca da eficiência e da eficácia nas instituições, com a menor quantidade possível de recursos investidos.

Em outro relato, o diretor da escola afirma que "o conselho escolar tem efetivamente atuado e a escola mostra ser mais sensível às necessidades e os problemas, sobretudo dos pais e alunos, possibilitando a participação de toda comunidade na definição dos rumos que a escola toma" (DIRETOR 2). O mesmo diretor ainda relata que realiza eleições para cada segmento ocupante das cadeiras do conselho, tendo como base a formação recebida no PNFCE. A partir destas reuniões surgiram projetos para melhoria do espaço escolar e grupos de estudos para professores.

Diante deste relato percebemos que, de alguma forma, parece que a formação obtida e a implementação das ações propostas pelo PNFCE, contribuiu para avanços nas propostas de organização do trabalho nesta escola. Contudo seria interessante poder verificar com os professores e demais sujeitos como de fato essas ações se realizam. Pois, concordamos com Dourado (2007), quando afirma que quando se trata de gestão 
democrática "é importante e necessário discernimos quais são as categorias que utilizamos. Percebe- se que há uma banalização quando se fala de democratização da gestão ou da administração, podendo nesse sentido, ser tudo ou não ser coisa nenhuma" (DOURADO, 2007, p. 156)

$\mathrm{Na}$ análise dos relatos, de forma geral, observamos uma pluralidade de concepções em relação à gestão democrática e à participação nos conselhos escolares: ora como espaço consultivo de caráter mais administrativo que pedagógico tal como registrado na escola do município de Toledo; ora como ambiente de produção e promoção de conhecimentos para a comunidade com a efetivação de grupos de estudos; ora como fomentadores de ações e projetos assistencialistas, tal como produção de chás beneficentes, nos quais os conselheiros atuam como auxiliares para a arrecadação de recursos financeiros para a escola via APMF, ou ainda como instrumento fiscalizador e regulamentador das ações e projetos políticos e pedagógicos das escolas.

Desta forma, há que se levar em consideração que cada escola é uma instituição que tem necessidades e formas de organização específicas, no que diz respeito à operacionalização da gestão, o que inviabiliza homogeneizar e simplificar a análise da efetivação dos conselhos escolares em cada uma delas, pois, essa pluralidade tem que se dimensionada.

\section{Cadernos do Programa Nacional de Fortalecimento dos Conselhos Escolares e análise das concepção de cidadania e democracia}

No primeiro caderno : Conselhos Escolares: Democratização da escola e construção da cidadania, temos as concepções de cidadania e democracia como conquista histórica da democratica representataiva, porém fazendo um parelelo com democracia participativa e representativa, entendemos ambos são termos antagonicos e que não se equiparam.

E democracia segundo Ruiz (2009. Pg.6), está para além de espaços eletivos, é algo a ser contruido e levado em conta históricamente

O significado de democracia, na sociedade atual, necessita ir além e incluir as diversas formas, meios e esforços de se buscar o entendimento entre grupos diversos e pessoas que os compõem, tendo sempre em vista os valores que não são inatos, porém, constituem construção histórica e coletiva da humanidade. 
Porém no Caderno 1, observamos que as duas formas de democrácia são concomitantes, mostrando assim um distanciamentoto da participação popular, uma vez que , segundo Cortina (2001),a democracia participativa,vincula-se a á uma “despolitização do público",ou seja atua de forma na qual os individuos ficao refens de ações de delegações de poder ou, nas quais não se tornam políticamente atauantes e pensantes, mas sim meros “delegadores de poder".

\section{Vejamos}

Construímos, assim, a democracia representativa, em que todos os dirigentes são eleitos por votos dos cida- dãos (presidente da República, governadores, prefeitos, senadores, deputados e vereadores). As conquistas históricas trazidas por essa democracia representativa serão ampliadas e novos avanços reais para a grande maioria da população serão conquistados quando a democracia for se tornando, cada vez mais, uma democracia participativa. Esta amplia e aprofunda a perspectiva do horizonte político emancipador da democracia. Isto é: uma democracia em que todos os cidadãos, como sujeitos históricos conscientes, lutam pelos seus direitos legais, tentam ampliar esses direitos, acompanham e controlam socialmente a execução desses direitos, sem deixar de cumprir, em contrapartida, os deveres constitucionais de todo cidadão. (CADERNO 1,MEC, 2006, p.18).

Está democracia na qual temos sujeitos conscientes e que entendem seu papel na sociedade, é o que deveria aplicar na escola no Conselho Escolar, onde os conselheiros aplicam as funções administrativas, financeiras e consultivas, com isto teríamos um democracia integral e não mera função consultiva. E de acordo com os textos do Caderno vemos uma lacuna em qual modelo de democracia seguir e que não rompe com a desburocratização dos espaços burocraticos. Em uma mesma formação onde apresentam que "Democracia e cidadania não combinam nem admitem uniformidade , padrão e modelo"(Caderno 6.pg.24), ao longo do curso colocam em que para gestão democrática existe um modelo a ser seguido, ou seja é completamente contraditório ora fala em democracia representativa , outra em participação comunitária. Segundo Gohn (2001,p.18) “a participação comunitária também é um derivatico da concepção liberal. Ela concebe o fortalecimento da sociedade cicil em termos de intregraçãi ,dos orgãoes representativos da sociedade aos orgaões deliberativos e administrativos do Estado."

Autora Gohn (2003, p. 25) ainda coloca que a "usualmente se considera participação política como um processo relacionado ao número e intensidade de indivíduos envolvidos na tomada de decisão", articulando-se diretamente com a 
questão da democracia representativa.

No caderno 6 - Conselho Escolar como espaço de formação humana: círculo de cultura e qualidade da educação, podemos comprovar esta lacuna, quando caderno coloca que a participação e a construção da democracia é responsabilidade da comunidade local e ainda serve como meio de inclusão social, porém é muito contraditório este pesnamento, pois como tornar a comunidade responsavel por algo que ela muitas vezes não participa ativamente.

Nesta perspectiva de construção da cidadania e da democracia participativas, demanda um trabalho pedagógico coletivamente assumido pela comunidade escolar e local[...]Trata-se de construir no coletivo um projeto de ação e de trabalho educativo escolar que impulsione a qualidade da educação com inclusão social, levando em consideração as demandas da comunidade local. Caderno 6 - Conselho Escolar como espaço de formação humana: círculo de cultura e qualidade da educação. Pg.23

O PNFCE, assim como os demais programas atuais do governo federal para a educação, centra-se em experiências individuias e reforça a meritocracia, destacando algumas escolas que têm êxito na condução dos mesmos. Apresentamos agora alguns relatos destas "experiências exitosas" registradas por escolas que se inscreveram para participar do PNFCE. Esses relatos estiveram disponíveis no site do Programa em uma espécie de banco de dados, que registrou a implantação do Conselho e o que deu certo com o Programa.

\section{Considerações Finais}

Neste estudo, concluímos que a concepção de gestão democrática e de participação, difundida pelo PNFCE se pauta na lógica das políticas para a educação difundidas após a década de 1990, na qual a parceria entre escola e comunidade é vista como condição sem a qual não é possível alcançar a qualidade na escola. Contudo é 
necessário questionar sobre essa concepção redentora e também sobre as condições concretas e objetivas diante das quais a gestão democrática é efetivada.

Entendemos que sua operacionalização pode sim contribuir para melhorias nas escolas uma vez que a comunidade possa participar da elaboração do projeto da escola e que se alie a esta instituição, no sentido de unir forças para cobrar do poder público mais investimento e valorização da educação pública, assim como de seus profissionais.

Defendemos isso, pois, ao mesmo tempo em que o governo federal preocupa-se em difundir uma política democrática nas escolas, para almejar a ampliação da qualidade, o PNE (2011-2020), elaborado nas CONAES e votado em 2014 indica uma necessidade de ampliação de recursos financeiros destinados à educação e para outros elementos importantes para a valorização desta área. E também uma maior as metas que tangem a gestão democrática

Meta 19: assegurar condições, no prazo de 2 (dois) anos, para a efetivação da gestão democrática da educação, associada a critérios técnicos de mérito e desempenho e à consulta pública à comunidade escolar, no âmbito das escolas públicas, prevendo recursos e apoio técnico da União para tanto.

19.2) ampliar os programas de apoio e formação aos (às) conselheiros (as) dos conselhos de acompanhamento e controle social do Fundeb, dos conselhos de alimentação escolar, dos conselhos regionais e de outros e aos (às) representantes educacionais em demais conselhos de acompanhamento de políticas públicas, garantindo a esses colegiados recursos financeiros, espaço físico adequado, equipamentos e meios de transporte para visitas à rede escolar, com vistas ao bom desempenho de suas funções;

19.3) incentivar os Estados, o Distrito Federal e os Municípios a constituírem Fóruns Permanentes de Educação, com o intuito de coordenar as conferências municipais, estaduais e distrital bem como efetuar o acompanhamento da execução deste PNE e dos seus planos de educação;

19.4) estimular, em todas as redes de educação básica, a constituição e o fortalecimento de grêmios estudantis e associações de pais, assegurando-selhes, inclusive, espaços adequados e condições de funcionamento nas escolas e fomentando a sua articulação orgânica com os conselhos escolares, por meio das respectivas representações;

19.5) estimular a constituição e o fortalecimento de conselhos escolares e conselhos municipais de educação, como instrumentos de participação e fiscalização na gestão escolar e educacional, inclusive por meio de programas de formação de conselheiros, assegurando-se condições de funcionamento autônomo; 
19.6) estimular a participação e a consulta de profissionais da educação, alunos (as) e seus familiares na formulação dos projetos político-pedagógicos, currículos escolares, planos de gestão escolar e regimentos escolares, assegurando a participação dos pais na avaliação de docentes e gestores escolares;

19.7) favorecer processos de autonomia pedagógica, administrativa e de gestão financeira nos estabelecimentos de ensino;

19.8) desenvolver programas de formação de diretores e gestores escolares, bem como aplicar prova nacional específica, a fim de subsidiar a definição de critérios objetivos para o provimento dos cargos, cujos resultados possam ser utilizados por adesão. (BRASIL, 2010, p. 14).

Essa conclamação pela qualidade, fortalecimento da gestão democrática e aumento da participação nas escolas públicas, caminham de forma morosa, não tendo nenhuma dessas estratégias ressaltadas nos dias atuais. Falta ainda promover condições reais e objetivas, pautadas em políticas de Estado eficientes, resulta num fenômeno no mínimo contraditório.

Finalizando, reiteramos que o fortalecimento dos conselhos escolares, proposto pelo PNFCE, configura-se como uma ação importante para a efetivação da gestão democrática da educação e para participação da comunidade em seu interior. Entretanto, tal programa, fica em nível das boas ideias e intenções se não houver políticas públicas integradas que proporcionem condições de trabalho e de vida para que todos os segmentos da comunidade escolar possam dispor de condições efetivas para participarem dos referidos conselhos.

\section{Referências}

ALVES, A. V. V. Para que fortalecer os conselhos escolares? Web Revista Diálogos \& Confrontos. Revista em Humanidades. jan. jun. 2012. p.47-59. Disponível em: http://www.uems.br/dialogoseconfrontos/Arquivos/PARA\%20QUE\%20FORTALECE R\%200S\%20CONSELHOS\%20ESCOLARES-1.pdf. Acesso em: 06 set. 2014.

BRASIL. Constituição - República Federativa do Brasil, capítulo III. Da Educação, da Cultura e do Desporto. Arts. 205 ao 214.

\section{BRASIL. Lei de Diretrizes e Bases da Educação Nacional Nº 9394/96 l.}

BRASIL. Programa Nacional de Fortalecimento dos Conselhos Escolares, Ministério da Educação / Secretaria de Educação Básica, Brasília - DF, novembro, 2004. 
Planejando a Próxima Década: Conhecendo as 20 Metas do Plano Nacional de Educação. Ministério da Educação / Secretaria de Articulação com os Sistemas de Ensino (MEC/SASE), 2014. Disponível em:

http://pne.mec.gov.br/pdf/pne_conhecendo_20_metas.pdf Acesso em: 10 abril. 2015.

BORDIGNON, Genuíno. Natureza dos conselhos de educação. In: Pró-Conselho. MEC. Brasília, 2004.

Gestão democrática da educação. In: Boletim Salto Para o Futuro, Boletim 19 outubro, p. 6-8., Brasília: MEC, 2005.

BENEVIDES, M. V. A cidadania ativa: referendo, plebiscito e iniciativa popular. São Paulo: Ática, 1998.

BORDIGNON, G.; GRACINDO, R. V. Gestão da educação: município e escola. In: FERREIRA, N. S.; AGUIAR, M. A. (Org.). Gestão da Educação: impasses, perspectivas e compromissos. São Paulo: Cortez, 2001.

CURY, Carlos R. Jamil. Os conselhos de educação e a gestão dos sistemas. São Paulo. Cortez, 2000.

CURY. Carlos Roberto Jamil. Conselhos de educação: fundamentos e funções. RBPAE - v.22,n. 1, p. 41-67, jan./jun. 2006.

DOURADO, L. F. A escolha de dirigentes escolares: Políticas e gestão da educação no Brasil. In: FERREIRA, N. S. (Org.). Gestão Democrática da Educação: atuais tendências, novos desafios. 5.ed. São Paulo: Cortez, 2006.

DOURADO, Luiz Fernandes. Políticas e gestão da educação básica no Brasil: limites e perspectivas. Educ. Soc., Campinas , v. 28, n. 100, Oct. 2007 . Disponivel em m $<$ http://www.scielo.br/scielo.php?script=sci_arttext\&pid=S0101-

73302007000300014\&lng=en\&nrm=iso>. 2015. http://dx.doi.org/10.1590/S010173302007000300014. Acessado em 21/02/2015.

FERREIRA, N. S. C. A gestão da educação e as políticas de formação de profissionais de educação: desafios e compromissos. In: Gestão democrática da educação. 4.ed. São Paulo: Cortez, 2003.

Repensando e ressignificando a gestão democrática da educação na "cultura globalizada". Educ. Soc. [online]. 2004, vol.25, n.89, pp. 1227-1249. ISSN 0101-7330. http://dx.doi.org/10.1590/S0101-73302004000400008. Acessado $20 / 02 / 2015$

FRIGOTTO, G. A produtividade da escola improdutiva. 3ed. São Paulo: Cortez, Autores Associados, 1989. 
GOHN, M. G. Conselhos Gestores e Participação sociopolítica. São Paulo: Cortez, 2001. (Coleção questões da nossa época, $n^{\circ} 84$ ).

OLIVEIRA, Dalila Andrade (Org.). Gestão democrática da educação: desafios contemporâneos. Petrópolis: Vozes, 1997.

Políticas educacionais no governo Lula: rupturas e permanências. RBPAE - v. 25, p. 197-209, mai/ago. 2009.

OLIVEIRA, João Batista A. e SCHWARTZMAN, Simon. A escola vista por dentro. Belo Horizonte. Alfa Educativa Editora, 2002.

PARO, Vitor H. Administração escolar. Introdução crítica. São Paulo: cortez, 2002

Gestão democrática da escola pública. São Paulo: Ática, 1997.

PERONI, V. M. V. A democratização da educação em tempos de parceria entre o público e o privado. R. Educação Pública, Cuiabá. v. 9. N. 40. P. 215-227. maio. ago., 2010. p. 215-228. Disponível em: http://www.ie.ufmt.br/revista/. Acesso em: 06 set. 2014.

RUIZ, Maria José Ferreira. Lutas populares e democratização da escola pública no estado do Paraná (1983 a 2010). 2013. 203 f. Tese (Doutorado em Educação) Faculdade de Filosofia e Ciências, Universidade Estadual Paulista, Marília, 2013.

VALENTE, Ivan; ROMANO, R. PNE: Plano nacional de educação ou carta de intenção? Educação e Sociedade. Campinas, v. 23, n. 80, p. 96-107, set. 2002. Disponível em: www.scielo.br/pdf/es/v23n80/12926.pdf. Acesso em: 03 set. 2009.

WERLE, F.O.C. Conselhos Escolares: implicações na gestão da Escola Básica. Rio de Janeiro: DP\&A, 2003.

WEFFORT, F. Qual Democracia? 2aed. São Paulo: Cia das Letras, 1996. 